\title{
3 Research Square

\section{Assessment of HCV viral load, genotype, liver biomarkers and clinical symptoms: Developing a mathematical model for prediction of HCV load}

Samira Basharkhah

Payame Noor University Faculty of Basic Sciences

Faezeh Sabet

Mashhad University of Medical Sciences

Hamid Reza Jahantightigh

Mashhad University of Medical Sciences

Sanaz Ahmadi Ghezeldasht

Academic Center for Education Culture and Research

Arman Mosavat

Academic Center for Education Culture and Research

Elham Barati

Mashhad University of Medical Sciences

Khosrow Shamsian

Academic Center for Education Culture and Research

Masoud Saleh Moghaddam

Payame Noor University

Hiva Sharebyani

Mashhad University of Medical Sciences

Tahereh Hassannia

Tehran University of Medical Sciences

Seyed Ali Akbar Shamsian ( $\sim$ ShamsianAA@mums.ac.ir)

Mashhad University of Medical Sciences https://orcid.org/0000-0001-5048-4857

Research article

Keywords: Hepatitis C viral load, HCV genotype, Clinical manifestations, Liver biochemistry, qRT-PCR, Northeastern Iran

Posted Date: March 28th, 2019

DOI: https://doi.org/10.21203/rs.2.515/v1 
License: (c) (i) This work is licensed under a Creative Commons Attribution 4.0 International License. Read Full License 


\section{Abstract}

Background Hepatitis $C$ virus infection is a major worldwide public health problem with about 1.75 million new HCV cases and 71 million HCV chronic infections around the world. The aim of study was to evaluate clinical, serological, molecular, and liver markers to develop a mathematical predictive model for HCV viral load quantification in chronic HCV infected patients. Methods In this cross-sectional study, blood samples were taken from 249 recently diagnosed HCV-infected subjects and were tested for liver condition, viral genotype, and HCV RNA load. Receiver operating characteristics (ROC) curves and multiple linear regression analysis were used to predict HCV viral load. Results The genotype 3 followed by genotype 1 were the most prevalent genotypes in Mashhad, Northeastern Iran. HCV viremia was significantly associated with genotyping $(p=0.04)$. The maximum levels of viral load were detected in the mixed genotype group, and the lowest levels in the undetectable genotype group. Log of HCV viral load was significantly associated with thrombocytopenia and higher serum levels of alanine transaminase (ALT). In addition, log HCV RNA was significantly higher in patients with arthralgia, fatigue, fever, vomiting or dizziness. Moreover, genotype 3 was significantly associated with icterus. A ROC curve analysis revealed that the best cut-off points for serum levels of aspartate aminotransferase (AST), ALT, and alkaline phosphatase (ALP) were $>31,>34$, and $\leq 246 \mathrm{IU} / \mathrm{L}$, respectively. Sensitivity, specificity and positive predictive values for AST were $87.7 \%, 84.36 \%$ and $44.6 \%$, for ALT; $83.51 \%, 81.11 \%$ and $36 \%$, and for ALP were $72.06 \%, 42.81 \%$ and $8.3 \%$, respectively. Conclusions A mathematical regression model was developed that can estimate the HCV viral load. Regression model: log viral load=7.69-1.01×G3$0.7 \times G 1+0.002 \times A L T-0.86 \times$ fatigue.

\section{Background}

Hepatitis $\mathrm{C}$ virus (HCV) infection is a chronic liver disease that has a worldwide prevalence of $2.8-3 \%$ [1]. The highest prevalence of chronic HCV in the world has been reported in Central Asia and the Middle East [2]. According to epidemiological studies, the prevalence of HCV infection in Iran is estimated to be $50 \%-75 \%$ among the high-risk groups, such as intravenous drug users, while the prevalence among blood donors is relatively low, $0.03 \%-2.1 \%$ [3]. The virus is a causative agent of chronic liver disease and, in a significant proportion of infected patients, may lead to cirrhosis and/or hepatocellular carcinoma (HCC) and the subsequent need for a liver transplantation. Therefore, it is essential that individuals with HCV infection are identified at the earliest stage [4].

Throughout the world, variations in the HCV genome sequence are utilized to classify the virus according to seven major genotypes and 67 subtypes. The most prevalent genotypes are 1,2, and 3 , while the remaining four are confined to specific regions of the world [5]. Genotype 1 and genotype 3 are the most dominant HCV subtypes found among Iranian patients. The distribution of HCV genotype in Iran is similar to Northern Europe but different from that of other Middle Eastern countries. HCV genotyping is essential to determine the appropriate treatment strategy and to predict the potential treatment outcome. As such, genotyping should be performed in all cases of positive viremia in under resourced countries where new expensive antiviral therapies are not available $[3,6]$. 
There are specific and non-specific tests for diagnosing, monitoring, and treatment of HCV infection. The specific diagnostic methods include serological and virological assays and genotyping tests. Nonspecific tests include all para-clinical methods for the diagnosis of hepatitis such as liver biochemistry measurement, liver biopsy, and abdominal imaging. Each of the above-mentioned methods has their own sensitivity and specificity [7, 8]. Enzyme immunoassays are the most common serological assays for detecting HCV antibodies. However, false-negative results can be observed in patients with major immunosuppression (advanced HIV infection or organ transplantation recipients), patients with chronic renal failure on long-term hemodialysis, thalassemia patients, injecting drug users, and patients with acute or early HCV infection. Molecular virological techniques, such as RT-PCR, play an important role in the detection of active viremia and the identification of infected individuals in the antibody-negative phase to a high degree of specificity and sensitivity. However, these techniques require expert staff, specialized equipment, and reagents that may not be readily available. To overcome these problems, an $\mathrm{HCV}$ core antigen (HCV core Ag) method was developed that closely follows HCV RNA dynamics. It achieves a high degree of specificity and sensitivity and provides effective clinical monitoring of any treatment plans. Aside from sequencing methods, real-time PCR is among the most sensitive techniques for HCV genotyping. The major limitation of the HCV core Ag assay is that it offers a lower sensitivity than the RT-PCR method [5, 9-11].

Besides these limitations, the methods used to quantify viral load are very expensive and require specialized equipment. Likewise, they are not currently suitable for low-resource areas that have a high prevalence of HCV. Therefore, the use of low-cost diagnostic assays seems to be essential in low-income countries. The aim of the present study was to evaluate clinical, serological, molecular, and liver markers as a means of developing a mathematical predictive model to detect viremia in HCV-infected individuals.

\section{Methods}

\section{Patients and study design}

This cross-sectional study was conducted on 249 patients with confirmed chronic hepatitis $\mathrm{C}$ who were referred by Hepato-gastroenterologists, Internists and Infectious diseases specialists to Navid Lab and ACECR-Central Medical Lab (Academic Center for Education, Culture and Research, Razavi Khorasan, Mashhad, Iran), in Mashhad between July 2012 and December 2015. The exclusion criteria were coinfection with HIV, hepatitis B virus, autoimmune diseases, absence of viral infections, and history of treatment for HCV infection. Blood samples were collected from patients and stored in sterile EDTAcontaining vacutainer tubes. Sera were measured for laboratory markers of liver function (platelet count, bilirubin, albumin, aspartate aminotransferase (AST), alanine aminotransferase (ALT), anti-HCV Ab. Plasma HCV viral load and genotype were determined using commercial kits. The clinical symptoms and demographic characteristics of the patients were collated using a standard checklist. The control group for ROC curve analysis consisted of 1,278 individuals, as follows: 595 females (46.6\%) and 683 males $(53.4 \%)$ with the mean age of $44.56 \pm 16.58$ years. 


\section{HCV-RNA quantification and genotype determination}

RNA was extracted from plasma samples using QIAamp Viral RNA Mini Kit (Qiagen, Germany) according to the manufacturer's instructions. According to the literature, the hepatitis $C$ virus genotypes that are most commonly encountered in Iran are type 1, 3, and 2. A real-time PCR-based, TaqMan method, adjusted for Iranian patients (HCV Genotype RG kit, Novin Gene, Iran), was carried out to determine HCV genotypes in the plasma specimens. Fluorescent labeled probes by Rotor-Gene Q 6000 (Qiagen, Germany) allow detection and determination of amplified product. The results were then analyzed using Rotor-Gene Q software.

\section{Biomedical markers}

AST, ALT, Alkaline phosphatase (ALP), serum platelet count, serum total protein, and serum albumin (Alb) were measured by autoanalyzer machine (Mindray BS-800M, USA).

\section{Statistical analysis}

The data were analyzed using SPSS software Version 16 (SPSS, Chicago, IL, USA), MedCalc Version 15.8 (Ostend, Belgium) and SAS Version 9.4 (North Carolina, USA). Quantitative variables were described as mean and standard error (SEM) and the categorical variables as number and percentage. The normality of the data was checked using the one-sample Kolmogorov-Smirnov test and the Shapiro-Wilk test where appropriate. The relation between nominal variables was assessed using Chi-square and Fisher exact test (when the expected number of observations was less than five in each cell). For scale variables, the Student's $t$-test, one-way ANOVA analysis of variance, and the Kruskal-Wallis test were used. Multiple linear regression models with a backward approach were used to establish a predictive model. The linear correlation between two variables was calculated using the Pearson correlation method. Receiver operating characteristic (ROC) curve analysis was used to obtain cut points for each biomarker which differentiate HCV infected patients from healthy individuals. The optimal cutoff points were verified according to the Youden's index and their corresponding sensitivity, specificity, and positive and negative predictive values were presented. The $P$-values less than 0.05 were considered to be statistically significant.

\section{Results}

\section{Demographic data and clinical features}

A total of 249 subjects with a mean age of $42.85 \pm 0.77$ years participated in the research. Of these, 45 (18.1\%) were female, and $204(81.9 \%)$ were male. The mean age of the females was $46.02 \pm 2.02$ years while that of the males were $42.15 \pm 0.82$ years. The difference between male and female was not significant. The clinical manifestations observed in the patients were as follows: fatigue $45(18.1 \%)$, dizziness 24 (9.6\%), arthralgia 22 (8.8\%), abdominal discomfort 21 (8.4\%), fever 20 (8\%), decreased 
appetite 19 (7.6\%), icterus 17 (6.8\%), dark urine 16 (6.4\%), nausea 15 (6\%), clay-colored stools $11(4.4 \%)$, vomiting $10(4 \%)$ and diarrhea 8 (3.2\%).

The mean HCV viral load was 5,198,244 $\pm 137,139.3 \mathrm{copies} / \mathrm{mL}$ (Min=100 copies $/ \mathrm{mL}$, Max= 29,257×104 copies $/ \mathrm{mL}$ ). The log HCV RNA in the patients was $5.44 \pm 0.08$ copies $/ \mathrm{mL}: 5.18 \pm 0.19$ copies $/ \mathrm{mL}$ in females and $5.5 \pm 0.09$ copies $/ \mathrm{mL}$ in males. The mean serum levels of ALT, AST, and ALP were $90.41 \pm$ $7.25,77.35 \pm 4.7$, and $228.69 \pm 12.86$, respectively. In control group, the mean serum levels of ALP, ALT, and AST were $305.46 \pm 7.55$ (IU/L), $27.86 \pm 1.23$ (IU/L), and 33.22 \pm 6.31 (IU/L), respectively.

Genotype 3 was the most prevalent genotype followed by genotype 1; $116(46.6 \%)$ and $106(42.6 \%)$, respectively. The genotype was undetectable in 11 patients (4.4\%). A total of 13 individuals $(5.2 \%)$ had genotype 2 , and only three individuals had a mixed genotype (1.2\%). The most risk factor for infection, were imprisonment, having a positive family history, sexual intercourse, bloodletting and tattoo. The demographic data and clinical features of the patients according to different genotype groups of HCV infection are shown in Table 1.

\section{HCV viral load associations}

Log of HCV RNA did not differ between males and females (5.19 \pm 0.19 copies/mL versus $5.5 \pm 009$ copies $/ \mathrm{mL}$, respectively, $p=0.1)$. The log of viral load in patients with hepatitis $C$ decreased with age; however, this finding was not statistically significant $(p=0.1)$. Moreover, there was a statistically significant association between log HCV RNA and genotype group $(p=0.04)$. Log of HCV RNA was significantly different between the genotype 1 group and the undetectable genotype group and also between the mixed and undetectable genotype groups. Log of HCV viral load increased significantly with increasing in ALT serum level and decreasing in platelet count, $(r=0.2, p=0.02, r=-0.25, p=0.03$, respectively). However, there was no significant association between log of HCV viral load and AST, ALP and Alb serum levels. Among the clinical manifestations, log HCV RNA was significantly higher in patients who had arthralgia, fatigue, fever, vomiting or dizziness $(p=0.02, p=0.0001, p=0.009, p=0.04$, $p=0.02$, respectively).

\section{HCV genotypes associations}

No significant association was found between HCV genotypes and gender, age, serum levels of AST, ALT, Alb, and ALP, and platelet count. However, $50 \%$ of the subjects who had dark urine and $35.3 \%$ of those with icterus were of genotype 3 ( $p=0.008$ and $p=0.006$, respectively). Table 2 shows the association between genotypes.

\section{Diagnostic values of liver biomarkers}

To determine the optimal cutoff points of the liver biomarkers for detection of HCV-infected patients, ROC curves were calculated, and specificity plus sensitivity were maximized. As shown in Fig 1a, the ROC curve analysis revealed that the AST cutoff of $>31 \mathrm{IU} / \mathrm{L}$ as a surrogate marker for the detection of HCV 
infection had a sensitivity of $87.7 \%$, a specificity of $84.36 \%$, a positive predictive value (PPV) of $44.6 \%$, and a negative predictive value (NPV) of $98 \%$. The prognostic value of ALT for the detection of HCV infection was $>34 \mathrm{IU} / \mathrm{L}$ with a sensitivity, specificity, PPV, and NPV of $83.51 \%, 81.11 \%, 36 \%$, and $97.5 \%$, respectively (Fig 1b). The sensitivity, specificity, PPV, and NPV of ALP for HCV infection were $72.06 \%$, $42.81 \%, 8.3 \%$, and $95.5 \%$ (Fig $1 \mathrm{C}$ ). The best cutoff point was $\leq 246 \mathrm{IU} / \mathrm{L}$. The area under the curve (AUC) values for AST, ALT, and ALP were $0.876,0.812$, and 0.59 , respectively. All the values were statistically significant $(p \leq 0.0001$, Fig 1$)$.

\section{Multivariable linear regression analysis for prediction of HCV viral load}

A multiple linear regression analysis with backward approach was performed to develop a mathematical model by which it was possible to predict HCV viral load. All variables including HCV genotypes, serum ALT, and clinical manifestation, such as arthralgia, fatigue, fever, vomiting or dizziness, were entered into the model. Moreover, the genotype variable was set as one of three indicator variables and the mixed genotype was set as a reference category. To assess the best model, backward method with removal probability of 0.1 has been used. Finally based on $R^{2}$ coefficient and after eliminating variables with multicollinearity, ALT, genotypes and fatigue were identified significant. Values for tolerance among these four variables ranged from 0.2-0.9 and variance inflation factors ranged from 1-5. The regression coefficients are shown in Table 3. Genotype 2, arthralgia, fever, vomiting, and dizziness, were excluded from the model $(p>0.1)$. The final regression model was as Eq. (1): Log viral load= $7.69-1.01 \times$ G3 $-0.7 \times$ $\mathrm{G} 1+0.002 \times$ ALT-0.86 $\times$ fatigue

As can be seen in Eq. (1), if the genotype of a patient is 3 or 1 (in comparison with mixed genotype), the mean predicted value of the log viral load would be reduced to 1.01 and 0.7 units, respectively. Similarly, in the case of patients who exhibit symptoms of fatigue, the model predicts that the log of viral load would be increased by 0.86 units. In this model, coding should be as follows: in patients with genotype 1 , specify 1 as $\mathrm{G} 1$ and 0 as G3 and vice versa for genotype 3 . If the patient has fatigue, use 1 as the fatigue input in the model; if he or she doesn't suffer from fatigue, use 0 . Evaluating of regression assumptions were summarized in Table 4.

For evaluating validity of the model we have conducted a 10 -fold cross validation, in the sense that each time, one of the $k$ subsets is used as the test set and the other $k-1$ subsets are put together to form a training set. Then, the average error across all $k$ trials is computed (Table 5 and 6 ). Two of the popular measures of the model performance in cross-validation are the Root Mean Square Error (RMSE) and the mean absolute error (MAE). In our model the RMSE equals to 1.03 and MAE is 0.85 . Figure 2 also illustrated log of viral load versus fitted values.

\section{Discussion}

$\mathrm{HCV}$ infection is a major worldwide public health problem with about 1.75 million new HCV cases and 71 million chronic infections around the world that causes hepatitis, cirrhosis, and hepatocellular cancer [12]. 
The early identification and effective management of the infection could be change the natural progression of the disease [13]. Viral load measurement is a key predictive factor that can be employed to develop successful treatment interventions [8]. In the present study, as reported by previous works [14, 15], genotype 3 followed by genotype 1 were the most prevalent genotypes. The maximum levels of HCV viremia were detected in the mixed genotype group, and the lowest levels were found in the undetectable genotype group. Although, viral load is considered to be an important prognostic factor in determining patients' treatment, the relationship between viral load and genotype and disease progression remains controversial [16].

The present study found a significant association between HCV viral load and lower platelet count as well as higher serum levels of ALT. However, no significant association was found between viral load and serum levels of Alb and ALP and AST. Moreover, there was no significant association between log of HCV viral load, age and gender. Some previous works have also failed to identify such a relationship [17-19]. In contrast, Willems et al. previously reported that serum transaminases could not be considered as useful surrogate markers for the identification of HCV carriers in chronic hemodialysis patients [20]. In a crosssectional study carried out on 2,336 patients with HCV, no correlation was observed between HCV viremia levels and serum markers including ALT, AST, ALP and hemoglobin for genotype 3a. However, significant correlations were found only between viral load and AST in genotype $3 \mathrm{~b}$ and between viral load and ALP in genotype 1a, [17]. These discrepancies could be related to factors such as heterogeneity in HCV genetic variants, ethnicity and period of infection, and variations in the populations and sample size studied [21].

Chronic HCV infection is often asymptomatic, although symptoms are usually nonspecific, mild, and intermittent. Fatigue is the most common symptom; however, other symptoms may include dizziness, weakness, nausea, loss of appetite, arthritis, fever, and weight loss [22-24]. Aydeniz et al. assessed rheumatic manifestations in HBV and HCV patients and their association with viral load and liver fibrosis. They reported that fatigue and arthralgia are significantly associated with viral load [25]. The current study identified significantly elevated levels of HCV viremia in patients with arthralgia, fatigue, fever, vomiting or dizziness. In addition, genotype 3 was significantly associated with dark urine and icterus manifestations.

Several biochemical and molecular assays are now available for the diagnosis, monitoring, and clinical management of chronic HCV infection [5]. In various studies, the optimal cut-off point of some noninvasive markers of liver fibrosis has been determined using ROC curve analysis [26]. Nassef et al. identified specific biomarkers that can predict fibrosis in liver biopsies among hepatitis $C$ virus-infected Egyptian children. The authors determined that the best cut-off values for AST and ALT were $18 \mathrm{IU} / \mathrm{L}$ and $20 \mathrm{IU} / \mathrm{L}$, respectively. The sensitivity, specificity and PPV for AST were $96.90 \%, 45.12 \%$ and $99.30 \%$, respectively and for ALT were $84.24 \%, 23.23 \%$ and $86.43 \%$, respectively. Therefore, the researchers suggested that AST represented a better indicator of liver fibrosis than ALT [27]. Notably, the serum AST and ALT showed a better sensitivity, specificity, and PPV for diagnosis of HCV infection. These results emphasize the utility of AST and ALT as an indicator of HCV infection rather than ALP. 
The measurement of HCV RNA load has been introduced as a useful approach for monitoring disease progression and treatment response [5]. In developing countries, most of the HCV infected cases could not be diagnosed and treated due to limited resources. Therefore, simpler, less expensive, and more rapid, methods and/or algorithms are required for the quantification of HCV viremia $[5,28]$. Recently, Kao et al. used signal-to-cut $(\mathrm{S} / \mathrm{CO})$ ratio of anti-HCV antibody to predict $\mathrm{HCV}$ viremia among a hemodialysis population. They demonstrated that a cut-off S/CO ratio of $>65$ had $100 \%$ specificity, $80.1 \%$ sensitivity, and $100 \%$ positive predictive value for discriminating HCV viremia from non-viremia [29].

In the present study, HCV viremia-associated factors were entered into the mathematical model to predict HCV viral load (Eq. 1). According to this model, for example, in a real patient with genotype 1, an ALT of $136 \mathrm{IU} / \mathrm{L}$ and no fatigue manifestation, the log of HCV viral load measured by real-time PCR was 5.6 copies/mL. Using mathematical model, the predicted log of HCV viral load was calculated as 5.2 copies $/ \mathrm{mL}$. In another patient with genotype 3 , symptoms of fatigue, ALT=65 IU/L, the log of HCV viral load was 4.8 copies $/ \mathrm{mL}$. In the mathematical model, the predicted log of HCV viral load was calculated at 5.3 copies $/ \mathrm{mL}$.

\section{Conclusions}

In conclusion, the present study demonstrated that log of HCV viral load is significantly associated with HCV genotypes, high ALT serum level, low platelet count, and arthralgia, fatigue, fever, vomiting, and dizziness manifestations. We suggested a mathematical algorithm that was based on a multiple linear regression analysis to predict HCV viral load. In this model, log of HCV viral load was equal to 7.69$1.01 \times G 3-0.7 \times G$ 1+0.002×ALT-0.86× fatigue.

\section{Abbreviations}

HCV, Hepatitis C virus; HIV: Human immunodeficiency virus; ALT, Alanine transaminase; AST, Aspartate aminotransferase; ALP, Alkaline phosphatase; Alb, Albumin; ROC, Receiver operating characteristic.

\section{Declarations}

\section{Ethics approval and consent to participate}

All procedures performed in studies involving human participants were in accordance with the ethical standards of the institutional and/or national research committee and with the 1964 Helsinki declaration and its later amendments or comparable ethical standards. This study was reviewed and approved by the Biomedical Research Ethics Committee of Payam-e-Noor University, Mashhad, Iran

[IR.PNU.REC.2352739]. Informed consent was obtained and signed from all individual participants included in the study.

\section{Consent for publication}


Not applicable.

\section{Availability of data and materials}

The datasets generated and/or analyzed during the current study are included in this paper and available from the corresponding authors [T. Hassannia and SAA. Shamsian].

\section{Competing interests}

The authors declare that they have no competing interests.

\section{Funding}

This study was financially supported by ACECR-Central Medical Lab (Academic Center for Education, Culture and Research, Razavi Khorasan, Mashhad, Iran) and Navid Medical Lab (No. 2352739).

\section{Author's contributions}

Doing experiments: SB, FS, HRJ, EB and HS; Manuscript drafting: SA and AM; Research advisors preparing experimental facilities and Kits: MS and KS; Research director, Conception and design of the study, Data analysis: TH and SAS. All authors have read and approved the final manuscript.

\section{Acknowledgments}

The authors have great thanks to the Navid Medical Lab, Mashhad, Iran, for very kind and valuable efforts for qRT-PCR performances. This study is a subject of M.Sc. thesis in Payam-e-Noor University, Mashhad, Iran.

\section{Author details}

${ }^{1}$ Department of Biochemistry, Faculty of Science, Payam-e-Noor University, ZIP Code: 9189896311 , Mashhad, Iran. ${ }^{2}$ Immunology Research center, Inflammation and Inflammatory Diseases Division, Faculty of Medicine, Mashhad University of Medical Sciences, Azadi-Square, Medical Campus, ZIP Code: 9177948564, Mashhad, Iran. ${ }^{3}$ Blood Borne Infections Research Center, Academic Center for Education, Culture and Research (ACECR), Razavi Khorasan, Azadi-Square, Ferdowsi University Campus, ZIP Code: 9177949367, Mashhad, Iran. ${ }^{4}$ Metabolic Syndrome Research Center, Faculty of Medicine, Mashhad University of Medical Sciences, Azadi-Square, Medical Campus, ZIP Code: 9177948564, Mashhad, Iran. ${ }^{5}$ Department of Internal Medicine, Faculty of Medicine, Arash Hospital, Tehran University of Medical Sciences, Tehran, Iran. ${ }^{6}$ Departments of Mycology and Parasitology, Faculty of Medicine, Mashhad University of Medical Sciences, Azadi-Square, Medical Campus, ZIP Code: 9177948564, Mashhad, Iran.

\section{References}


1. Hajarizadeh B, Grebely J, Dore GJ. Epidemiology and natural history of HCV infection. Nat Rev Gastroenterol Hepatol. 2013;10(9):553-62.

2. Guerra J, Garenne M, Mohamed MK, Fontanet A. HCV burden of infection in Egypt: results from a nationwide survey. J Viral Hepat. 2012;19(8):560-7.

3. Khodabandehloo M, Roshani D. Prevalence of hepatitis C virus genotypes in Iranian patients: a systematic review and meta-analysis. Hepat Mon. 2014;14(12):e22915.

4. Zhang K, Wang L, Lin G, Li J. Is Anti-Hepatitis C Virus Antibody Level an Appropriate Marker to Preclude the Need for Supplemental Testing. Intervirology. 2015;58(5):310-7.

5. Riaz S, Bashir MF, Haider S, Rahid N. Association of genotypes with viral load and biochemical markers in HCV-infected Sindhi patients. Braz J Microbiol. 2016;47(4):980-86.

6. Jahanbakhsh Sefidi F, Keyvani H, Monavari SH, Alavian SM, Fakhim S, Bokharaei-Salim F. Distribution of hepatitis $C$ virus genotypes in Iranian chronic infected patients. Hepat Mon. 2013;13(1):e7991.

7. Chevaliez S, Pawlotsky JM. Hepatitis $C$ virus serologic and virologic tests and clinical diagnosis of HCV-related liver disease. Int J Med Sci. 2006;3(2):35-40.

8. Mukherjee R, Burns A, Rodden D, Chang F, Chaum M, Garcia N, et al. Diagnosis and Management of Hepatitis C Virus Infection. J Lab Autom. 2015;20(5):519-38.

9. Firdaus R, Saha K, Biswas A, Sadhukhan PC. Current molecular methods for the detection of hepatitis $C$ virus in high risk group population: A systematic review. World J Virol. 2015;4(1):25-32.

10. Gupta E, Bajpai M, Choudhary A. Hepatitis C virus: Screening, diagnosis, and interpretation of laboratory assays. Asian J Transfus Sci. 2014;8(1):19-25.

11. Reyes-Mendez MA, Juarez-Figueroa L, Iracheta-Hernandez P, Medina-Islas Y, Ruiz-Gonzalez V. Comparison of two diagnostic algorithms for the identification of patients with HCV viremia using a new HCV antigen test. Ann Hepatol. 2014;13(3):337-42.

12. EASL Recommendations on Treatment of Hepatitis C. . J Hepatol. 2018;69(2):461-511.

13. Cavalcante LN, Lyra AC. Predictive factors associated with hepatitis $C$ antiviral therapy response. World J Hepatol. 2015;7(12):1617-31.

14. Hajia M, Amirzargar A, Khedmat H, Shahrokhi N, Farzanehkhah M, Ghorishi S, et al. Genotyping Pattern among Iranian HCV Positive Patients. Iran J Public Health. 2010;39(2):39-44.

15. Zarkesh-Esfahani SH, Kardi MT, Edalati M. Hepatitis $C$ virus genotype frequency in Isfahan province of Iran: a descriptive cross-sectional study. Virol J. 2010;7:69.

16. Gallotta A, Paneghetti L, Mrazova V, Bednarova A, Kruzlicova D, Frecer V, et al. Development of a novel diagnostic algorithm to predict NASH in HCV-positive patients. Int J Biol Markers. 2018;33(2):231-36.

17. Ahmad W, ljaz B, Javed FT, Kausar H, Sarwar MT, Gull S, et al. HCV genotype-specific correlation with serum markers: higher predictability for genotype 4a. Virol J. 2011;8:293. 
18. Hadinedoushan $\mathrm{H}$, Salmanroghani H, Amirbaigy MK, Akhondi-Meybodi M. Hepatitis $\mathrm{C}$ virus genotypes and association with viral load in yazd, central province of iran. Hepat Mon. 2014;14(3):e11705.

19. Schijman A, Colina R, Mukomolov S, Kalinina O, Garcia L, Broor S, et al. Comparison of hepatitis C viral loads in patients with or without coinfection with different genotypes. Clin Diagn Lab Immunol. 2004;11(2):433-5.

20. Willems M, de Jong G, Moshage H, Verresen L, Goubau P, Desmyter J, et al. Surrogate markers are not useful for identification of HCV carriers in chronic hemodialysis patients. J Med Virol. $1991 ; 35(4): 303-6$.

21. Keshvari M, Alavian S, Behnava B, Miri S, Elizee PK, Tabatabaei S, et al. Distribution of hepatitis C virus genotypes in iranian patients with congenital bleeding disorders. Iranian Red Crescent Medical Journal. 2010;12(6):608.

22. Abdo AA. Hepatitis $C$ and poor quality of life: is it the virus or the patient? Saudi J Gastroenterol. 2008;14(3):109-13.

23. Nouroz F, Shaheen S, Mujtaba G, Noreen S. An overview on hepatitis C virus genotypes and its control. Egyptian Journal of Medical Human Genetics. 2015;16(4):291-98.

24. Patel K, Muir AJ, McHutchison JG. Diagnosis and treatment of chronic hepatitis C infection. BMJ. 2006;332(7548):1013-7.

25. Aydeniz A, Namiduru M, Karaoglan I, Altindag O, Yagiz E, Gursoy S. Rheumatic manifestations of hepatitis $B$ and $C$ and their association with viral load and fibrosis of the liver. Rheumatol Int. 2010;30(4):515-7.

26. Schiavon Lde L, Narciso-Schiavon JL, de Carvalho-Filho RJ. Non-invasive diagnosis of liver fibrosis in chronic hepatitis C. World J Gastroenterol. 2014;20(11):2854-66.

27. Nassef YE, Shady MM, Galal EM, Hamed MA. Performance of diagnostic biomarkers in predicting liver fibrosis among hepatitis $\mathrm{C}$ virus-infected Egyptian children. Mem Inst Oswaldo Cruz. 2013;108(7):887-93.

28. Njouom R, Tejiokem MC, Zanga MC, Pouillot R, Ayouba A, Pasquier C, et al. A cost-effective algorithm for the diagnosis of Hepatitis $\mathrm{C}$ virus infection and prediction of HCV viremia in Cameroon. J Virol Methods. 2006;133(2):223-6.

29. Kao HH, Chen KS, Lin CL, Chang JJ, Lee CH. Utilization of Signal-to-Cutoff Ratio of Hepatitis C Virus Antibody Assay in Predicting HCV Viremia among Hemodialysis Patients. Nephron. 2015;130(2):12733.

\section{Tables}




\begin{tabular}{lccccc}
\hline Table 1. Demographic data and clinical features in different genotype groups of HCV infection. \\
\hline Features ${ }^{1}$ & \multicolumn{5}{c}{ HCV genotypes } \\
\hline Gender & G1 & G2 & G3 & Mixed & Undetectable \\
& & & & genotype & \\
\cline { 2 - 6 } & & & & $1(2.2 \%)$ & $2(4.4 \%)$ \\
Female & $21(46.7 \%)$ & $2(4.4 \%)$ & $19(42.2 \%)$ & $2(1 \%)$ & $9(4.4 \%)$ \\
\hline Male & $85(41.7 \%)$ & $11(5.4 \%)$ & $97(47.5 \%)$ & \\
\hline Log of HCV RNA & $5.59 \pm 0.12$ & $5.11 \pm 0.47$ & $5.4 \pm 0.11$ & $6.74 \pm 0.17$ & $4.55 \pm 0.43$ \\
(Copies/mL) & & & & & \\
\hline AST (IU/L) & $77.32 \pm 8.69$ & $77.14 \pm 17.6$ & $79.21 \pm 5.8$ & $36.33 \pm 8$ & $71.88 \pm 19.49$ \\
\hline ALT (IU/L) & $89.6 \pm 9.15$ & $79.71 \pm 20.11$ & $95.1 \pm 12.48$ & $55 \pm 19.5$ & $67 \pm 15.48$ \\
\hline ALP (IU/L) & $240.06 \pm 20.96$ & $199 \pm 0$ & $232.94 \pm 16.58$ & $135 \pm 0$ & $104.67 \pm 17.7$ \\
\hline
\end{tabular}

${ }^{1}$ Categorical variables are presented as No. (\%) and Scale variables as (mean \pm SD).

Table 2: The association between Genotypes and liver function tests, HCV VL and age.

\begin{tabular}{lcccccc} 
& Age & VL & AST & ALT & ALP & Alb \\
\hline $\mathbf{1}$ \& 2 & $0.566^{*}$ & 0.195 & 0.539 & 0.812 & 0.787 & 0.105 \\
$\mathbf{1}$ \& 3 & 0.509 & 0.143 & 0.233 & 0.869 & 0.407 & 0.573 \\
$\mathbf{1}$ \& un & 0.168 & 0.047 & 0.819 & 0.502 & 0.008 & 0.740 \\
$\mathbf{2}$ \& un & 0.165 & 0.064 & 0.728 & 0.524 & 0.180 & 0.317 \\
$\mathbf{3}$ \& un & 0.213 & 0.111 & 0.542 & 0.460 & 0.010 & 0.416 \\
$\mathbf{2}$ \& 3 & 0.334 & 0.045 & 0.950 & 0.967 & 0.737 & 0.104 \\
\hline
\end{tabular}

P-value, Mann-Whitney test. un: undetectable genotype.

VL: Viral load; AST: aspartate aminotransferase; ALT: alanine transaminase; ALP: Alkaline phosphatase; Alb: Albumin. 


\begin{tabular}{lccc}
\hline \multicolumn{3}{l}{ Table 3. Comparison of Log HCV RNA in patients with and without clinical manifestations } \\
\hline Clinical manifestations & No. & $\begin{array}{c}\text { Median of } \\
\text { Log HCV RNA } \\
\text { (interquartile range) }\end{array}$ & $P$-value \\
\hline Arthralgia & 22 & $6.3(5.3-6.9)$ & 0.02 \\
yes & 227 & $5.3(4.6-6.2)$ & \\
no & & & 0.001 \\
Fatigue & 45 & $6.3(5.2-6.9)$ & \\
yes & 204 & $5.2(4.5-6.1)$ & 0.009 \\
no & & & \\
Fever & 20 & $6.4(5.6-6.9)$ & 0.04 \\
yes & 229 & $5.3(4.6-6.2)$ & \\
no & & $6.2(5.4-7)$ & 0.02 \\
Vomiting & 10 & $5.4(4.5-6.3)$ & \\
yes & 239 & $6.1(5-6.8)$ & \\
no & & $5.3(4.5-6.2)$ & \\
Dizziness & 24 & 225 &
\end{tabular}

Table 4. Regression coefficients.

\begin{tabular}{|c|c|c|c|c|c|}
\hline \multirow[t]{2}{*}{ Parameter } & \multicolumn{2}{|c|}{ Unstandardized Coefficients } & \multirow{2}{*}{$\begin{array}{c}\text { Standardized Coefficients } \\
\text { Beta }\end{array}$} & \multirow[b]{2}{*}{$\mathrm{t}$} & \multirow[b]{2}{*}{$P$-value } \\
\hline & $\mathrm{B}$ & $\mathrm{SE}$ & & & \\
\hline (Constant) & 7.694 & .476 & - & 16.148 & $<0.0001$ \\
\hline G 3 & -1.014 & .357 & -.440 & -2.843 & .005 \\
\hline G 1 & -.697 & .360 & -.300 & -1.935 & .055 \\
\hline $\mathrm{ALT}$ & .002 & .001 & .168 & 2.427 & .016 \\
\hline Fatigue & -.864 & .196 & -.306 & -4.409 & $<0.0001$ \\
\hline R-squared & & 0.16 & F- Lack of fit test & & 0.64 \\
\hline Adjusted R-squared & & 0.14 & Prob (Lack of fir) & & 0.932 \\
\hline S.E of regression & & 1.07 & F- Leven's test & & 1.46 \\
\hline Sum squared reside & & 199.9 & Prob (Leven's test) & & 0.204 \\
\hline Durbin Watson stat & & 2 & Prob (K-S normality test of & reside) & 0.2 \\
\hline
\end{tabular}

G1: Genotype 1; G3: Genotype 3; ALT: alanine transaminase. 
Table 5. Result of 10-fold cross validation.

\begin{tabular}{ccccc}
\hline Sample Replicate Number & F-value & \multicolumn{1}{c}{$\boldsymbol{P}$-value } & Adjusted R-squared & Root MSE \\
\cline { 5 - 6 } \cline { 5 - 5 } $\mathbf{1}$ & 6.67 & $<0.0001$ & 0.14 & 1.09 \\
$\mathbf{2}$ & 8.18 & $<0.0001$ & 0.17 & 0.99 \\
$\mathbf{3}$ & 5.66 & $<0.0001$ & 0.12 & 1.09 \\
$\mathbf{4}$ & 5.59 & $<0.0001$ & 0.11 & 1.08 \\
$\mathbf{5}$ & 5.17 & $<0.0001$ & 0.11 & 1.1 \\
$\mathbf{6}$ & 10.03 & $<0.0001$ & 0.2 & 1.07 \\
$\mathbf{7}$ & 6.86 & $<0.0001$ & 0.14 & 1.07 \\
$\mathbf{8}$ & 5.8 & $<0.0001$ & 0.12 & 1.12 \\
$\mathbf{9}$ & 6.55 & $<0.0001$ & 0.13 & 1.1 \\
$\mathbf{1 0}$ & 6.23 & $<0.0001$ & 0.13 & 1.04 \\
\hline
\end{tabular}

Table 6. Summary statistics of log viral load and fitted value by 10-fold cross validation.

\begin{tabular}{lcccrr}
\hline Variable & Mean & Std Dev & Sum & Minimum & Maximum \\
\hline Fitted value & 5.51005 & 0.47645 & 1873 & 4.85228 & 7.08415 \\
\hline Viral load & 5.48577 & 1.22981 & 2688 & 2.00000 & 8.46623 \\
\hline \multicolumn{7}{l}{ Pearson Correlation Coefficients: $\mathbf{0 . 3 5}(\boldsymbol{P}<0.0001)$} \\
\hline
\end{tabular}

Figures 

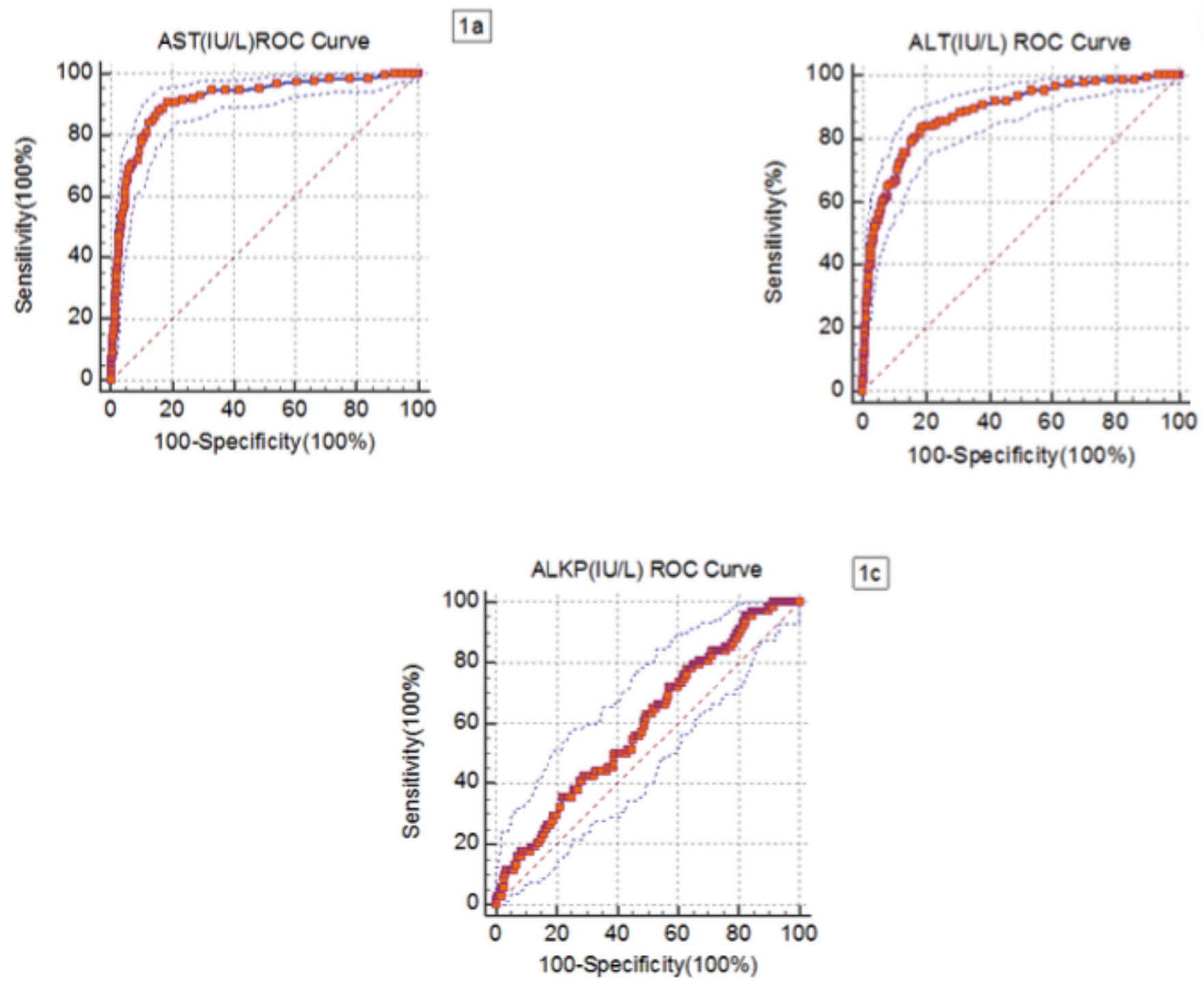

1c

\section{Figure 1}

Receiver characteristic curve (ROC) analysis of AST, ALT and ALP for progression of HCV infection. a) Cutoff point of $>31 \mathrm{IU} / \mathrm{L}$ for AST had $87.70 \%$ sensitivity, $84.36 \%$ specificity, $44.6 \%$ positive predictive value (PPV), and $98 \%$ negative predictive value (NPV). b) Cut off point of $>34 \mathrm{IU} / \mathrm{L}$ for ALT with a sensitivity of $83.51 \%$, specificity of $81.11 \%$, positive predictive value (PPV) of $36 \%$ and negative predictive value of $97.5 \%$. c) Cutoff point of $\leq 246 \mathrm{IU} / \mathrm{L}$ for ALP had $72.06 \%$ sensitivity, $42.81 \%$ specificity, $8.3 \%$ positive predictive value (PPV), and $95.5 \%$ negative predictive value (NPV). The area under the curve (AUC) values for AST, ALT and ALP were 0.876, 0.812, and 0.59, respectively. All the values were statistically significant $(p \leq 0.0001)$. 


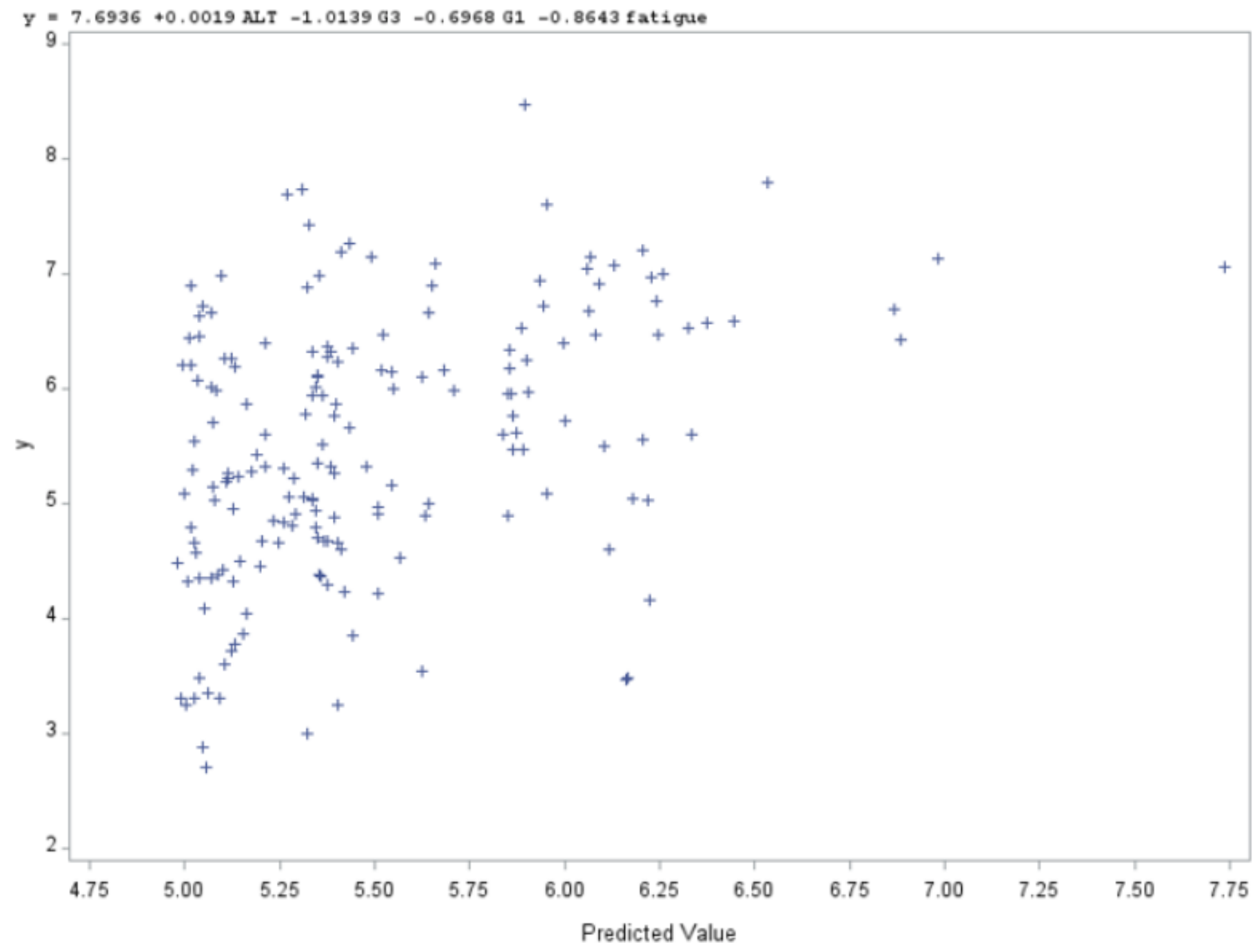

Figure 2

Plot of log viral load versus fitted values. 